\title{
On the dynamics and composition of the high-latitude thermosphere
}

\author{
T. L. Killeen, F. G. McCormac,* A. G. Burns, J. P. Thayer, $\dagger$ \\ R. M. JOHNSON and R. J. NICIEJEWSKI \\ Space Physics Research Laboratory, Department of Atmospheric, Oceanic and Space Sciences, \\ The University of Michigan, Ann Arbor, MI 48109, U.S.A.
}

(Received in final form 3 April 1991)

\begin{abstract}
Recent experimental measurements of the dynamics of the neutral upper thermosphere have demonstrated the important roles of ion-drag and Joule heating processes in establishing the basic neutral wind morphology and controlling neutral composition, particularly in the high-latitude region. Instruments on the Dynamics Explorer-2 spacecraft (DE 2), for example, were capable of measuring the three-dimensional vector neutral wind and ion drift in the thermosphere along the orbital track, together with constituent densities and temperatures. Ground-based optical and radar measurements of winds and temperatures from observatories in Greenland have contributed additional measurements of thermospheric neutral wind velocities and ionospheric parameters. The comprehensive nature of these various data sets has enabled more stringent experimental constraints to be placed on the numerical models of the region (thermosphere-ionosphere general circulation models, TIGCMs), leading to an improved theoretical understanding of the important physical processes that control thennospheric circulation and variability. In addition, the measurements have enabled the development of semi-empirical models of thermosphere dynamics which can be used in various theoretical studies. The Vector Spherical Harmonic (VSH) model, for example, provides a description of global thermospheric state variables (wind, temperature and density), using a combination of empirical data and NCAR-TIGCM calculations. This paper presents a brief review of some of the more recent progress made in this area by the team of researchers at the University of Michigan, with emphasis on the interpretation of experimental measurements made from DE 2 and from ground-based observatories in Thule and Søndrestrømfjord, Greenland. Comparisons between individual data sets from these sources and the VSH model are also presented.
\end{abstract}

\section{INTRODUCTION}

The dynamics, thermodynamics, and compositional structure of the neutral gas in the upper thermosphere are strongly controlled by ion-neutral collision processes, particularly at high geomagnetic latitudes. Magnetospheric convection electric fields map down into the high-latitude ionosphere along equipotential geomagnetic field lines and drive the charged particles there into cellular motion. Rapidly moving ions in these ionospheric convection cells can readily transfer momentum to the neutral gas via ion-drag forcing and can convert a portion of their kinetic energy of motion into internal energy of the neutral gas via Joule or collisional heating. In addition, the enhanced concentrations of ions associated with auroral particle precipitation serve to increase the rates of exchange of energy and momentum between the neutral and ionized species by increasing the magnitude of the ion-

\footnotetext{
* Now at The Radiocarbon Laboratory, Queens University, Belfast, U.K.

$\uparrow$ Now at The Geoscience and Engineering Center, SRI International, 333 Ravenswood $\Lambda$ venue, Menlo Park, CA 94025, U.S.A.
}

neutral collision frequency amongst other factors. The effect of these high-latitude ion-neutral collision processes is to modify the neutral wind, temperature and compositional structure away from the structure that would be expected if the only sources of energy for the thermosphere were solar UV and EUV insolation.

Many cxamples of the effects of auroral/ magnetospheric forcing of the neutral thermosphere at high latitudes have been reported in the literature over the past 10 years (e.g. see the review articles of Meriwether, 1983; Roble, 1983; MaYr et al., 1985 ; KILLEEN, 1987 ; KILleEN and Roble, 1988). Rapid experimental and theoretical progress has been sustained due, in part, to the comprehensive nature of new data sets provided by the NASA Dynamics Explorer-2 spacecraft (DE 2) and the groundbased network of optical interferometer observatories and incoherent scatter radar facilities, as well as to the maturity of the numerical, three-dimensional, time-dependent, thermosphere/ionosphere general circulation models (TIGCMs). The two best-developed examples of the latter are the National Center for Atmospheric Research model (NCAR-TIGCM) of DiCKINSON et al. (1981) and ROBLE et al. (1982, 
1988) and the University College London/Sheffield University model of FULLER-RoWELL and REEs (1980) and Fuller-Rowell et al. (1987). Two semi-empirical models of neutral thermosphere dynamics have also been developed in recent years, the Vector Spherical Harmonic (VSH) model of KuLLeEN et al. (1987) and the Horizontal Wind Model (HWM) of HForN et al. (1988, 1991). While the HWM model is entirely based on observations, the VSH model is a hybrid, based primarily on the theoretical calculations from the NCAR-TIGCM, but supplemented with DE2 measurements where available.

In this paper, we summarize some of the recent high-latitude results obtained using the DE2 thermospheric neutral wind, temperature and composition data, together with VSH model predictions. Additional experimental results from ground-based optical observatories sited at Thule and Søndrestrømfjord (Sondrestrom), Greenland and from the incoherent scatter radar at Sondrestrom are also shown. The emphasis of this discussion is on perturbations to the solar-driven upper thermospheric winds, temperatures and compositional structures due to forcing associated with high-latitude ionospherethermosphere coupling processes. In the following sections we (1) discuss the nature of the experimental measurements made on the DE 2 spacecraft and describe some recent results, (2) describe briefly the VSH model, some sample results, and experimentmodel comparisons using both satellite and groundbased measurements of high-latitude thermosphere dynamics, (3) discuss considerations pertaining to compositional perturbations at high latitudes, and (4) make some concluding remarks.

\section{DYNAMICS EXPLORER MEASUREMENTS}

The Dynamics Explorer-2 spacecraft payload included the Fabry-Perot interferometer, FPI (Hays et al., 1981), the Wind and Temperature Spectrometer, WATS (SPENCER et al., 1981), and the Neutral Atmosphere Composition Spectrometer, NACS (CARIGNAN et al., 1981). These instruments measured the meridional and zonal components of the neutral wind and neutral constituent abundances, respectively, along the track of the polar-orbiting satellite. Both the FPI and WATS instruments also measured neutral kinetic temperatures. In addition to these instruments, the Langmuir probe, LANG (KREHBIEL et al., 1981), the Ion Drift Meter, IDM (HeEus et al., 1981), and the Retarding Potential Analyzer, RPA (HANSON et al., 1981) measured the ion density and the zonal meridional components of the ion drift, respectively. The RPA and LANG instruments also enabled measurements of ion and electron temperatures, respectively. The comprehensive nature of the DE 2 data set has enabled various studies of thermospheric ion-neutral coupling at high latitudes to be conducted (see the review by KILLEEN and RoBle, 1988).

Fxamples of the DE 2 coverage for two nearly full orbits of the spacecraft are shown in Figs 1 and 2. These figures show, as a function of various geophysical parameters along the orbital track of the spacecraft, the following measured or derived observables (from top to bottom): (1) the neutral wind vector from FPI and WATS ; (2) the ion drift vector from IDM and RPA; (3) the atomic oxygen, molecular nitrogen and electron number densities from NACS and LANG, respectively; (4) the electron, ion, and neutral kinetic temperatures from LANG, RPA and FPI, respectively; and (5) vertical winds and ion drifts measured from WATS and IDM, respectively. The upper inset to the left of each figure is a dial showing the neutral winds (Fig. 2) or ion winds (Fig. l) in a geographic polar projection for the southern hemisphere. The lower inset provides information on the time history of the relevant interplanetary magnetic field (IMF) components and the $K_{p}$ and $A E$ geomagnetic indices prior to and at the time (given by the dotted vertical line) of the orbital pass. The vectors are plotted such that local noon is to the top of the diagram and local dawn to the right. Thus, the downward-directed ion drift vectors are in the anti-sunward direction and are generally associated with the central region of the northern and southern hemisphere geomagnetic polar caps, while the regions of upwarddirected ion drift vectors are in the sunward direction and are generally associated with the dawn and dusk sectors of the auroral zones.

Figure 1 presents data from orbit 7366 of DE 2 which occurred during Julian day 82338 . As can be seen from the lower inset, this orbit occurred during relatively quiet geomagnetic conditions, with $K_{p}=1+\left(A_{p}=13\right)$. By contrast, Fig. 2 shows data from orbit 7219 on day 82328 which was a period of intense geomagnetic activity, with $K_{p}=7\left(A_{p}=83\right)$. In both cases, the satellite obtained data across both northern (winter) and southern (summer) high-latitude regions, as well as low- and mid-latitudes. These data are shown to provide an overview of the variations in thermospheric state variables typically observed from DE 2 .

There are several general features that can be discerned from Figs I and 2. Most obviously, the neutral and ion winds (including the horizontal and vertical components) have their greatest structure and magnitudes in the two polar regions, with clear evidence 


\section{DE-2 FPI/WATS/RPA/IDM/NACS/LANG}

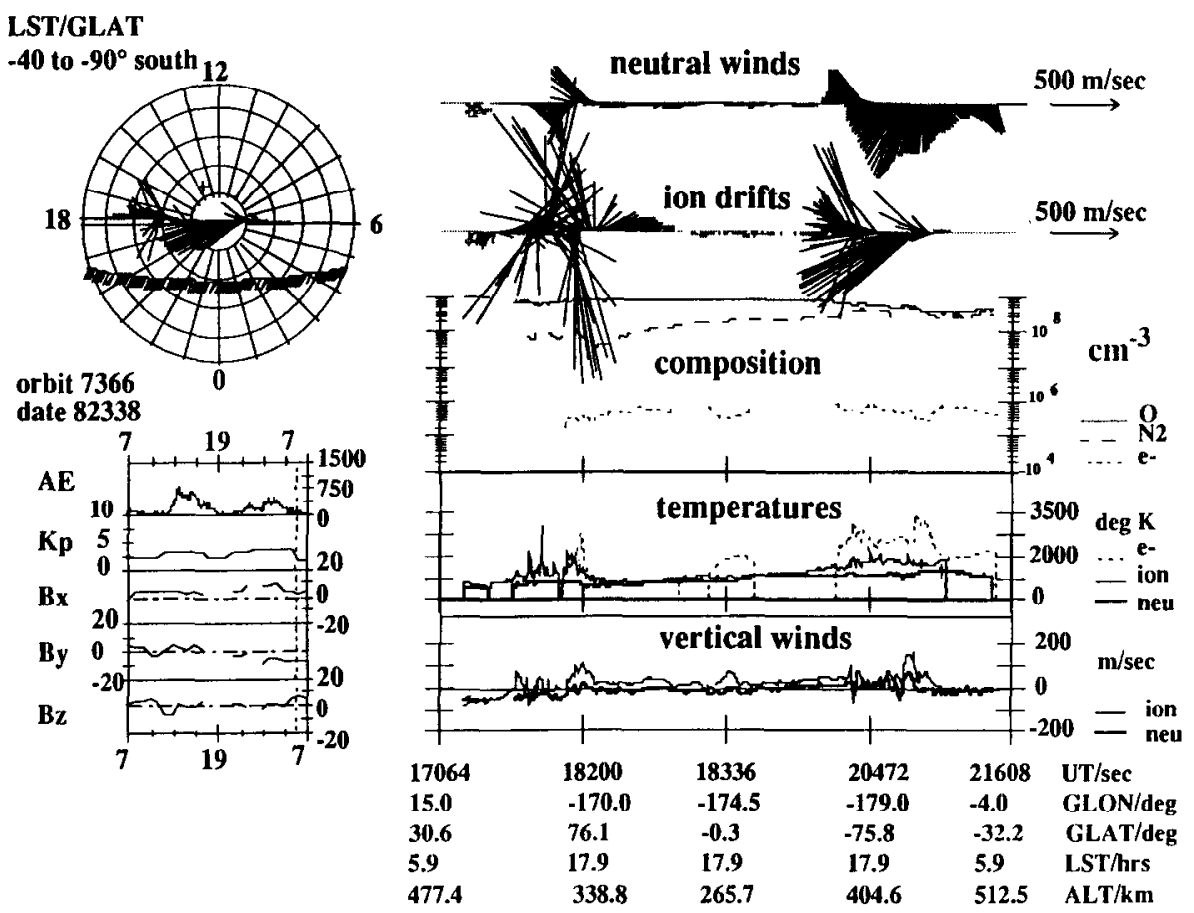

Fig. 1. Geophysical observables measured along the track of Dynamics Explorer 2 during orbit 7366 . The neutral winds and ion drifts are shown in the top two traces plotted against time, altitude, and latitude of the spacceraft as it successively passes (left-to-right) over the northern hemisphere (winter) polar region, the equatorial region and the southern hemisphere (summer) polar region. The second panel shows the atomic oxygen and molecular nitrogen densities, referred to a fiducial altitude of $300 \mathrm{~km}$, and the electron (ion) density. The third panel shows the electron (dotted line), ion (light line) and neutral (bold line) temperatures measured along the orbital track. The bottom trace shows the measured vertical neutral winds (bold line) and ion drifts (light line). The lower inset to the left shows the time history of the IMF components and the geophysical indices $A E$ and $K_{p}$ for the $24 \mathrm{~h}$ prior to the orbital pass. The mid-point UT for the satellite pass is denoted by the vertical dotted line. The upper inset to the left shows a polar dial (geographic latitude and solar local time) for the pass, with the ion winds plotted and the location of the geomagnetic pole given by the cross.

of a predominantly two-cell ion convection pattern and a morphologically similar, but less strong, neutral wind system at high latitudes. The neutral winds (and ion drifts) at mid- and low-latitudes (central region of figures) have much smaller magnitudes and are consistent with a day-to-night solar-driven global thermospheric wind system. The neutral composition measurements obtained during these passes have all been adjusted to an altitude of $300 \mathrm{~km}$ in order to highlight latitudinal rather than altitudinal changes, using a diffusive equilibrium approximation to map the measured values upwards or downwards from the corresponding spacecraft altitude for each measurement. The [O] and $\left[\mathrm{N}_{2}\right]$ densities, referred to $300 \mathrm{~km}$ altitude, show relatively smooth and unstructured behavior at mid- and low-latitudes, and more struc- tured perturbations at polar latitudes, in response to the temporally and spatially complex high-latitude ion drag and Joule heating processes. For both the quiettime orbit (7366) and the active-time orbit (7219), the $\mathrm{N}_{2}$ densities at $300 \mathrm{~km}$ equal or exceed the corresponding $\mathrm{O}$ densities in the summer hemisphere polar regions due to the extra heating and consequent upwelling of the thermosphere. The $\mathrm{O}$ densities do not show the strong summer-to-winter gradient observed in the $\mathrm{N}_{2}$ densities for the active period and, in fact, show decreases at high latitudes during the disturbance when $\mathrm{N}_{2}$ increases. These 'anomalies' are well understood and are related to the different masses of the species. It is also interesting to note that the vertical velocities tend to be more upwards in the warmer summer hemisphere and in regions of 

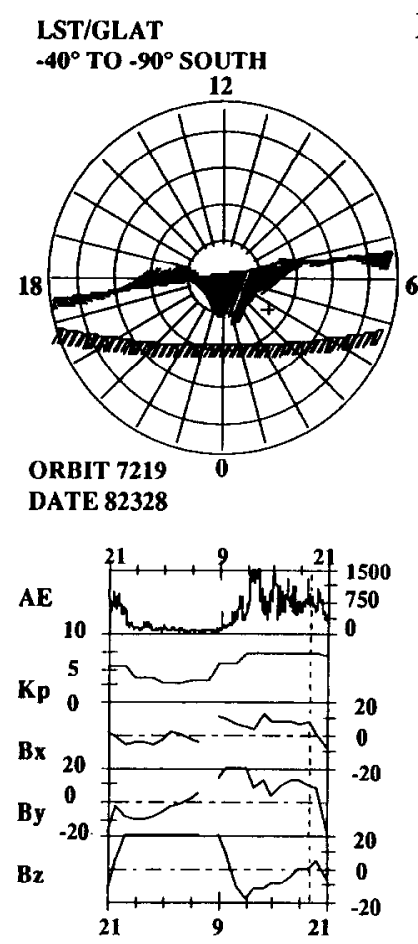

\section{DE-2 FPI/WATS/RPA/IDM/NACS/LANG}

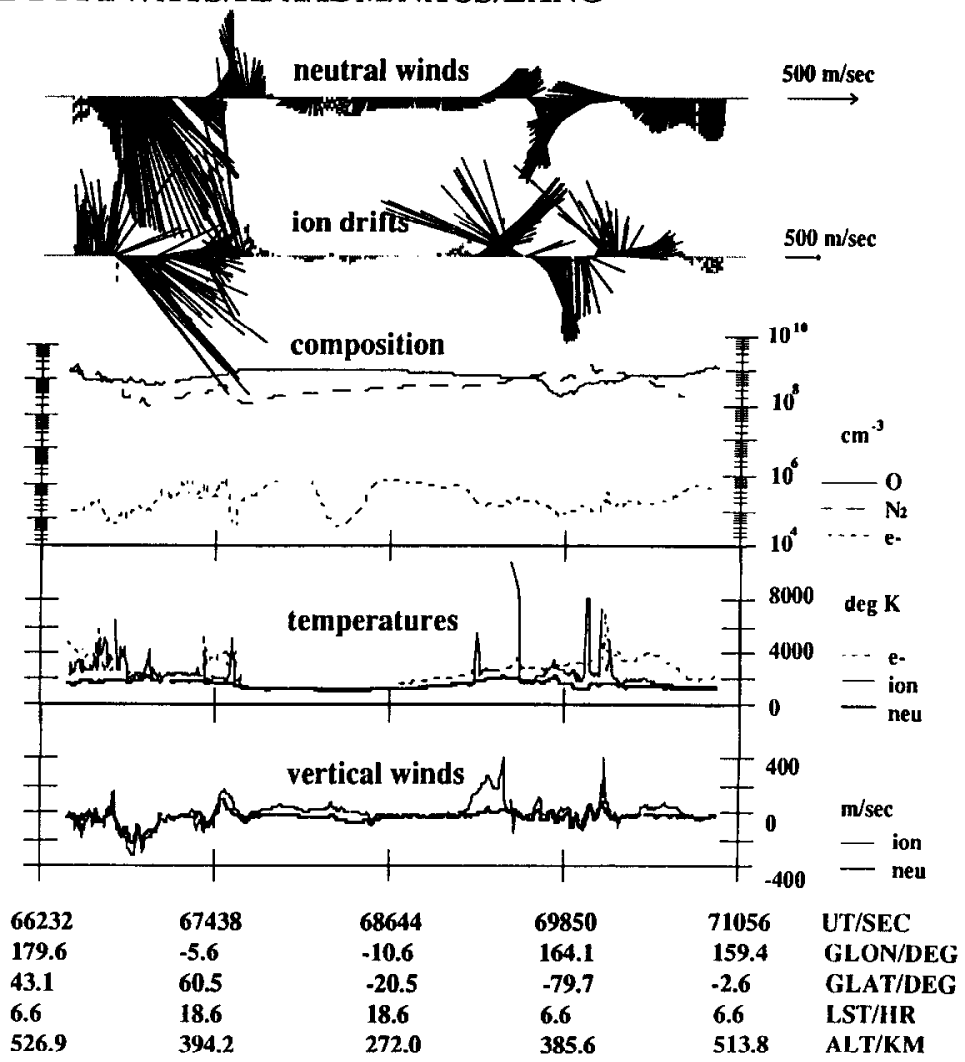

Fig. 2. Geophysical observables measured along the track of Dynamics Explorer 2 during orbit 7219 . The format of the figure is as for Fig. 1, with the exception that neutral winds rather than ion drifts are shown in the polar dial to the upper left.

enhanced auroral heating. The electron density $\left(n_{e}\right)$ measurements show various structures associated with ionospheric morphology. $\Lambda$ particular feature of interest occurs near $68200 \mathrm{~s}$ UT, where a depression in $n_{e}$ at equatorial latitudes is probably an altitude effect caused by the relatively high $\boldsymbol{F}$-region peak and the relatively low satellite altitude; in this region the satellite dips below the $F_{2}$ peak. The vertical wind measurements (bottom panel) show evidence for the presence of gravity wave activity at polar latitudes with various horizontal wavelengths, ranging from a few degrees to tens of degrees in latitude.

The measured ion, electron and neutral temperatures ( $T_{i}, T_{e}$ and $T_{n}$, respectively) along the orbital tracks provide insight into the thermal structure of the upper atmosphere. As expected, the magnitude of $T_{e}$ is the greatest of the three, except for localized regions of very strong Joule heating where $T_{i}$ can exceed $T_{e}$. Such a period occurred during the southern hemisphere polar passage for orbit 7219 , where the greatly enhanced frictional heating of the ions, due to the large ion neutral difference velocities, caused localized enhancements in ion temperature to many thousands of degrees. In general, all three species are in thermal equilibrium at low latitudes $\left(T_{e} \approx T_{i} \approx T_{n}\right)$, with major departures from that equilibrium occurring at high latitudes.

The effects of enhanced levels of geomagnetic activity can be seen by comparing the data of Fig. 1 and Fig. 2. The neutral and ion winds, neutral densities, and neutral and ion temperatures are typically all greater in magnitude during the more geomagnetically active orbit 7219 than during orbit 7366 . Neutral winds in excess of $1200 \mathrm{~m} / \mathrm{s}$ were observed near 67400 s UT on orbit 7219 , which occurred during an extended period of greatly enhanced geomagnetic activity (see, for example, the $A E$ trace in the lower inset of Fig. 2). These are the largest magnitude winds observed by DE and it is our belief that these are the 

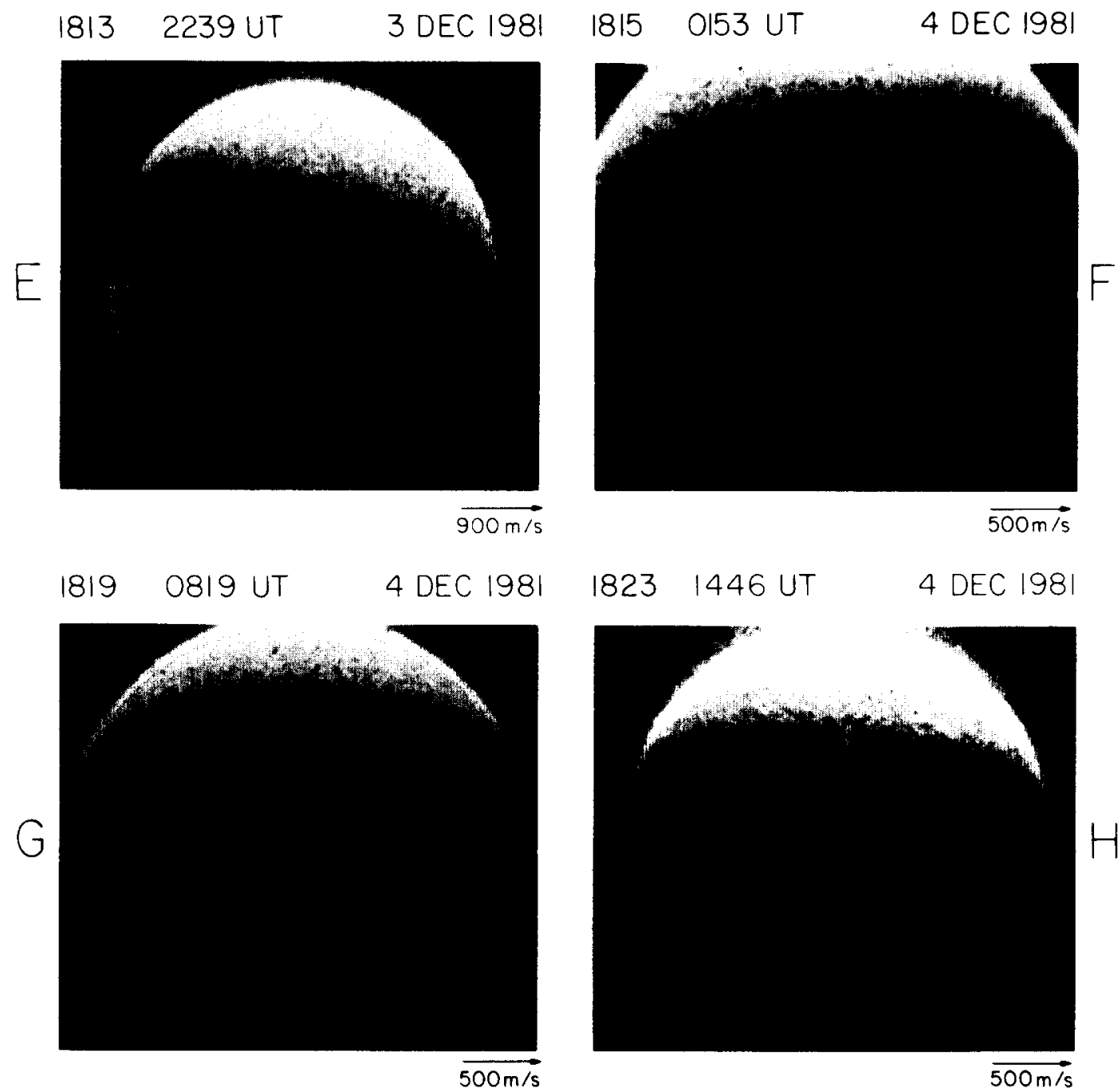
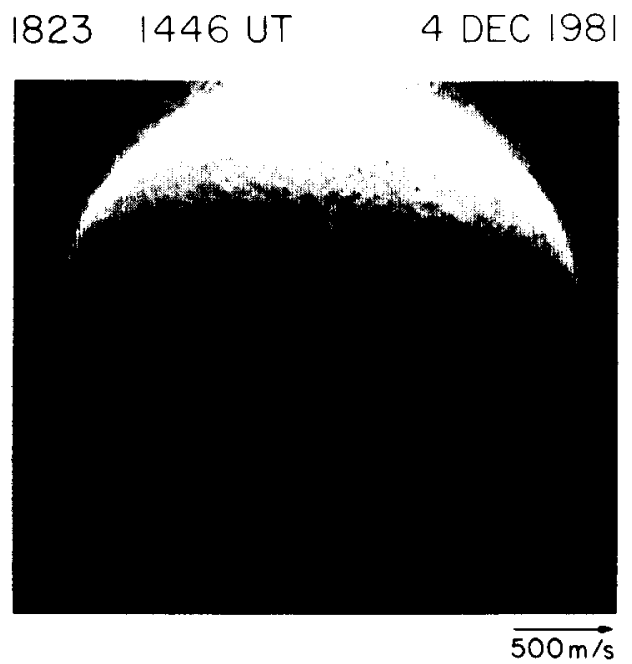

Fig. 3. Simultaneously measured neutral wind vectors from DE 2 (orbit 1813) and DE 1 auroral inlage (courtesy of L. A. Frank and J. D. Craven, University of Iowa). The images were obtained using the SpinScan Auroral Imager, SAI, on Dynamics Explorer 1, viewing the northern hemisphere aurorae at ultraviolet wavelengths. The images are false-color coded and are oriented such that the direction towards the Sun is to the top of the figure, dusk to the left. The solar terminator is evident, running roughly horizontal across each image, as is the entire auroral oval located just to the nightside of the terminator. The neutral wind vectors are denoted by the yellow arrows whose origins are positioned along the DE 2 orbital track. The wind scale is given at lower right. $3 \mathrm{~b}-\mathrm{d}$ are for DE 2 orbits 1815,1819 and 1823 , respectively. The figure is taken from KiLLEEN et al. (1988). 


\section{DE 2 FPI/WATS/IDM/RPA DAY 82328}
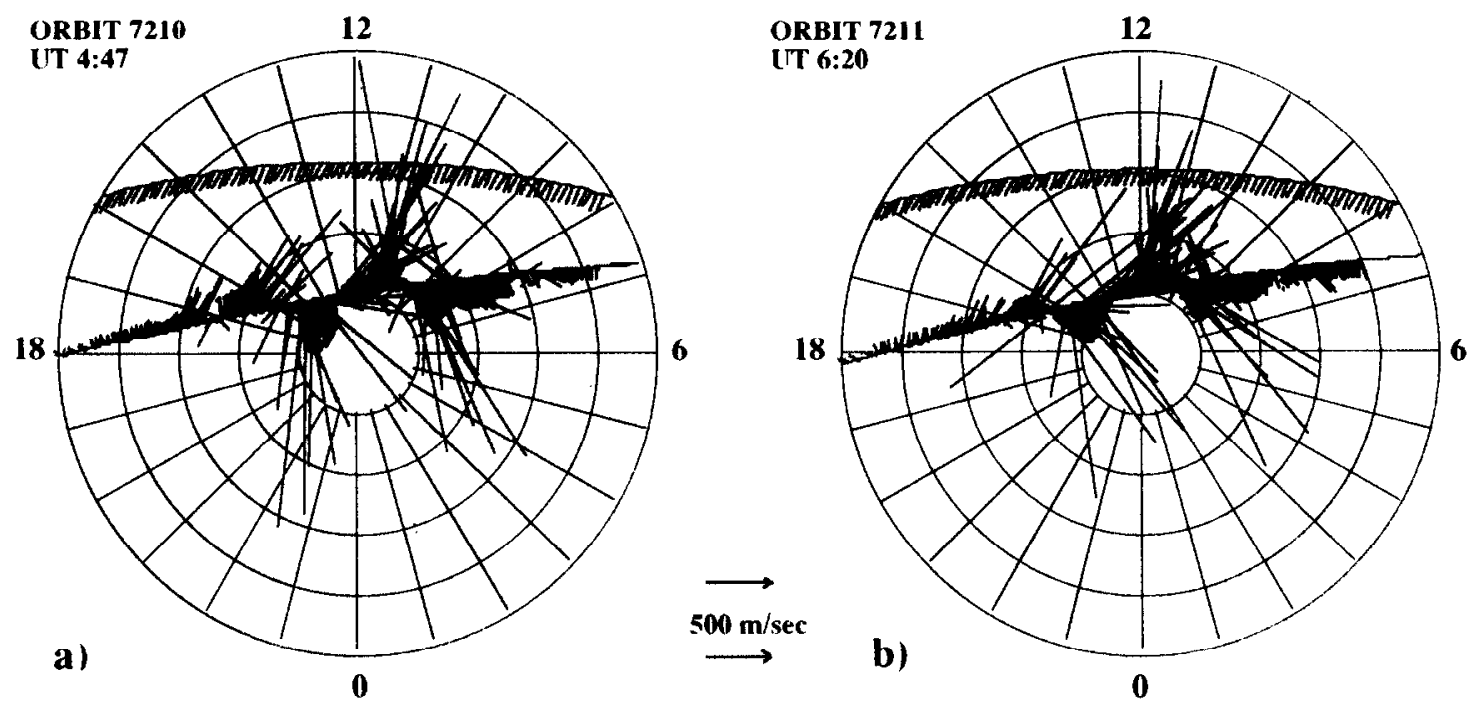

Fig. 7. Neutral winds and ion drift measurements (blue arrows and red bars, respectively) are plotted along the orbital track of Dynamics Explorer 2 during orbits 7210 and 7211 . The data are plotted in geomagnetic polar coordinates (magnetic local time and magnetic latitude), with the outer circle being at $40^{\circ}$ geomagnetic. These data were obtained during a prolonged period of strongly northward IMF. The figure is adapted from KILLEEN et al. (1985). 


\section{Neutral Winds and Temperatures}
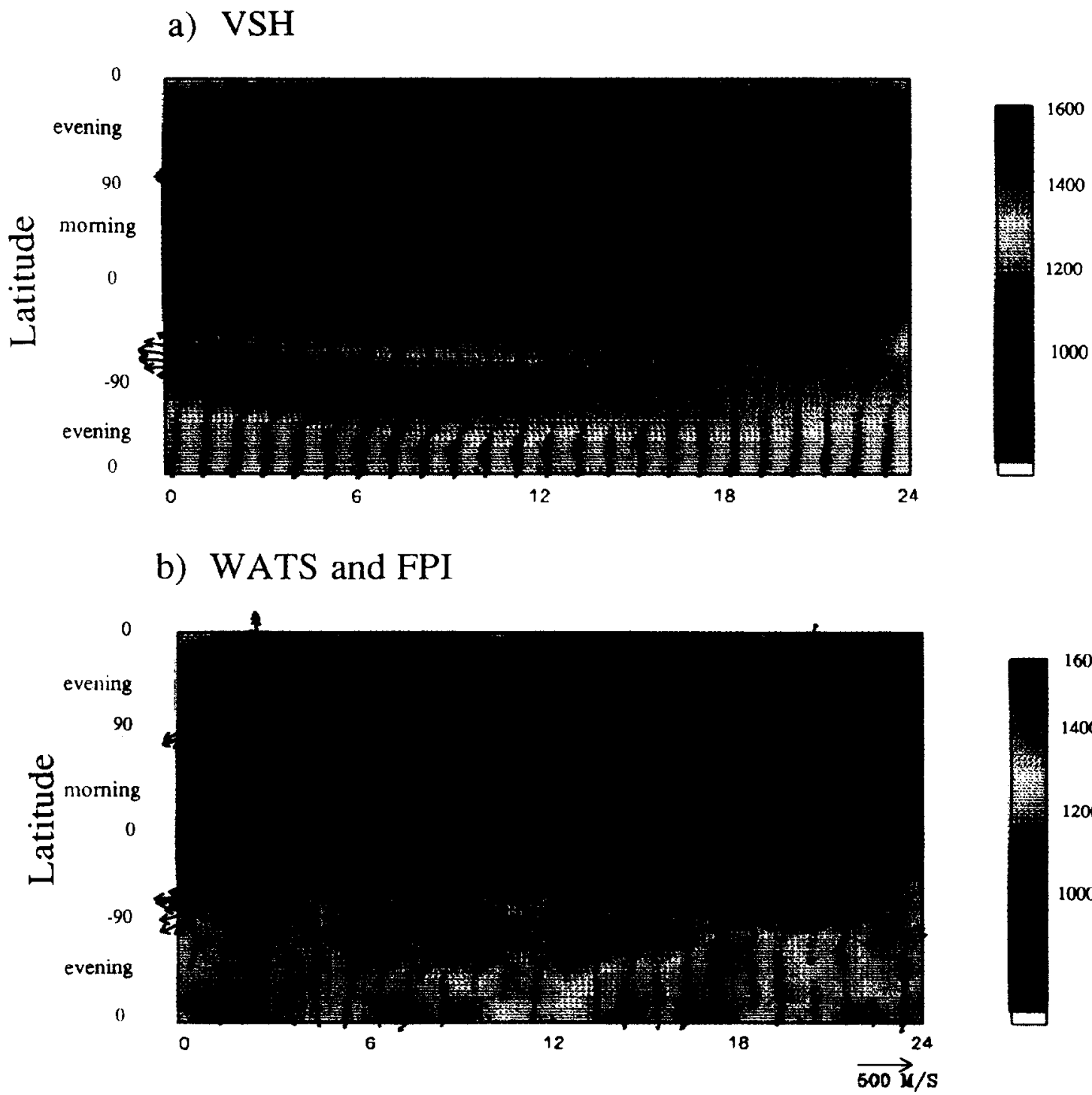

\section{Universal Time (hours)}

Fig. 10. Thermospheric wind and temperature plots for December solstice solar maximum conditions. (a) VSH model predictions; (b) averaged DE 2 winds and temperatures collected between November 1981 and January 1982 and between November 1982 and January 1983. The plots are in geographic latitude and Universal Time. 
largest magnitude winds yet reported for any part of the Earth's atmosphere.

While the study of thermospheric and ionospheric parameters from individual high-latitude orbital passes provides information on the response of the upper atmosphere to energy and momentum inputs from the magnetosphere, the study by KILLEFN et al. (1988) illustrated unambiguously the relationship between thermospheric winds and one of the most obvious manifestations of magnetuspheric processes-the visible aurora. Figure 3 shows simultaneous measurements of global-scale auroral luminosity distributions and vector neutral winds over the northern (winter) polar cap, using data from the spin-scan auroral imager, SAI (FrANK et al., 1981), on DE 1 and the FPI and WATS instruments on DE 2, respectively. This work illustrates the spatial relationship between large-scale morphological features of the $F$-region neutral wind field in the winter polar region and the location and spatial extent of the aurora. A definite correlation can be seen to exist between reversals and boundaries in the neutral wind field and the location of the visible auroral oval. Examples of such simultaneous data sets indicate that the neutral wind and boundaries closely follow the substormdependent expansion and contraction of the auroral oval.

\subsection{Dependence of high-latitude thermospheric circula- tion on magnetospheric/ionospheric forcing processes}

To study the dynamic response of the high-latitude thermosphere to various forcings in greater detail, data from many hundreds of DE 2 orbits, similar to those depicted in Figs 1 and 2, have been analysed. The FPI and WATS measurements of the two components of the upper thermospheric horizontal neutral wind vector, for example, have been binned and averaged according to various geophysical indices in order to investigate the mean response of the thermospheric neutral wind to forcings associated with the aurora. A primary conclusion is that above $60^{\circ}$ of latitude the neutral wind pattern in the upper thermosphere is best ordered in a geomagnetic coordinate system (Killeen et al., 1982; Roble et al., 1983; HaYs et al., 1984; ReEs et al., 1985). The high-latitude neutral winds are observed generally to follow, but lag behind, the pattern of ionospheric convection, with some important differences. Thus, in Fig. 1, for example, the neutrals and ions have qualitatively similar velocities (speed and direction) throughout the high-latitude regions, with some important differences. In general, for example, the neutrals have a stronger sunward component in the dusk sector of the auroral oval than in the dawn sector due to the differing effects of the Coriolis force for anticyclonic and cyclonic flow (KILLEEN and RoBLE, 1984).

MCCORMAC et al. (1987) used several hundred orbits of DE 2 over a six-month period to investigate quantitatively the dependence of the high-latitude thermospheric circulation on geomagnetic activity. Figure 4 shows the measured average neutral wind pattern using all available polar passes of DE 2 for active $\left(K_{p}>4\right)$ and quiet $\left(K_{p} \leqslant 3\right)$ geomagnetic conditions in both hemispheres. The data are plotted in geomagnetic polar coordinates (magnetic local time and magnetic latitude). In all four cases, the mean neutral circulation shows the imprint of momentum transferred from the twin-cell ionospheric convection pattern, with strong anti-sunward winds over the geomagnetic polar cap bounded by strong sunward winds in the dusk auroral sector and much weaker sunward or anti-sunward winds in the dawn auroral sector. The magnitudes of the neutral winds are generally greater for the high $K_{p}$ case than for the low $K_{p}$ case, as would be expected from the stronger auroral forcings.

THAYER et al. (1987) further investigated the sensitivity of the high-latitude neutral circulation pattern to the sign of the cast-west $\left(B_{y}\right)$ component of the interplanetary magnetic field (IMF). They used average neutral wind measurements from the same data base as the MCCORMAC et al. (1987) study, discussed above, to illustrate changes in the configuration of the neutral wind pattern that were clearly ordered by the sign of $B_{y}$. Simultaneous measurements of $B_{y}$ from the ISEE-3 spacecraft were used to select from and order the DE 2 neutral wind data. For this study, only data for which the north south $\left(B_{z}\right)$ component of the IMF was $\leqslant+1 n$ nT were used to avoid complications arising from the multi-cellular ion and neutral patterns known to exist for strongly northward IMF. Results from this study are shown in Fig. 5, in which data from $\sim 300$ orbits of DE 2 orbital passes have been separated according to the sign of $B_{y}$ and averaged into bins of geomagnetic latitude and geomagnetic local time for the two hemispheres.

The criteria used to separate the data sets according to $B_{y}$ involved the pre-existence of a definite positive or negative value for $B_{y}$ as measured by ISEE-3 for $1 \mathrm{~h}$ prior to the DE orbital pass. Passes occurring either during very high or very low levels of geomagnetic activity were excluded from the study and allowance was made for the propagation time to the Earth of the IMF measured at ISEE-3 altitudes. As can be seen from Fig. 5, there are significant differences in the mean thermospheric circulation patterns for $B_{y}$ positive and negative. To some extent the effects are 


\section{AVERAGED DE-2 NEUTRAL WIND DATA}
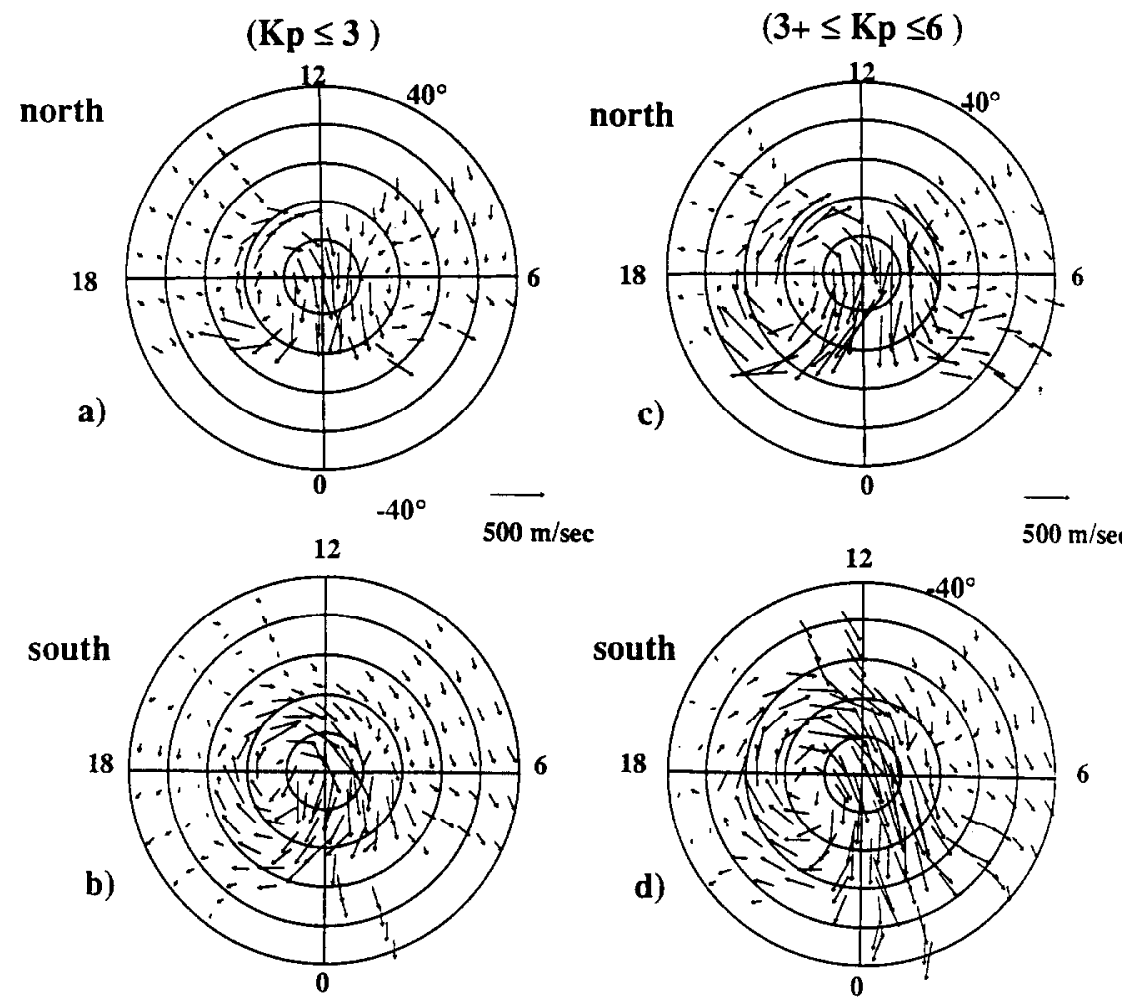

Fig. 4. Averaged upper thermospheric neutral wind measurements at $\sim 300 \mathrm{~km}$ altitude for (a) north pole low $K_{p}$; (b) south pole low $K_{p}$; (c) north pole high $K_{p}$; (d) south pole high $K_{p}$. Data collected between November 1981 and January 1982 and between November 1982 and January 1983 were averaged according to the given range of $K_{p}$ and plotted in geomagnetic polar coordinates (magnetic latitude and magnetic local time). The outer circle of each polar dial is at $40^{\circ}$ geomagnetic latitude.

mirrored between hemispheres; that is, a $B_{y}$ positive (negative) signature in the northern hemisphere resembles a $B_{y}$ negative (positive) signature in the southern hemisphere. In all cases, the average circulation patterns shown illustrate the dominance of the dusk anti-cyclonic neutral vortex mentioned above. The spatial magnitude of this vortex, however, is greater for $B_{y}$ positive conditions in the northern hemisphere and for $B_{y}$ negative conditions in the southern hemisphere. A distinct rotation in the direction of the polar cap anti-sunward flow that was dependent on the sign of $B_{y}$ was also noted.

To highlight the structural changes in the ncutral circulation pattern that are dependent on the sign of the $B_{y}$ component of the IMF, Fig. 6 shows the average anti-sunward neutral wind (i.e. that component of the neutral wind parallel to the noon-midnight magnetic meridian) on the nightside of the geomagnetic polar cap as a function of magnetic local time (MLT) for the magnetic latitude (MLAT) range $72.5-87.5^{\circ}$, where the data have been separated according to the sign of $B_{y}$ for both hemispheres (ThAYER, 1990). These plots illustrate more clearly the shift in location of the region of most rapid antisunward flow with a change in sign of $B_{y}$ and demonstrate the 'mirroring' between hemispheres of this characteristic feature of the neutral circulation. In the northern hemisphere when $B_{y}$ is positive (Fig. 6a), for example, the anti-sunward wind component reaches a maximum in the early morning sector at $\sim 0400$ MLT. When $B_{y}$ is negative, the maximum in the anti-sunward wind component occurs in the pre-midnight sector at $\sim 2200 \mathrm{MLT}$. These general results are reversed in the southern hemisphere, Fig. 6b. The locations of the various maxima in the anti-sunward polar-cap neutral wind are consistent with the locations of maxima in the $\boldsymbol{B}_{y}$-dependent convection electric fields discussed by HePpNer (1977). 

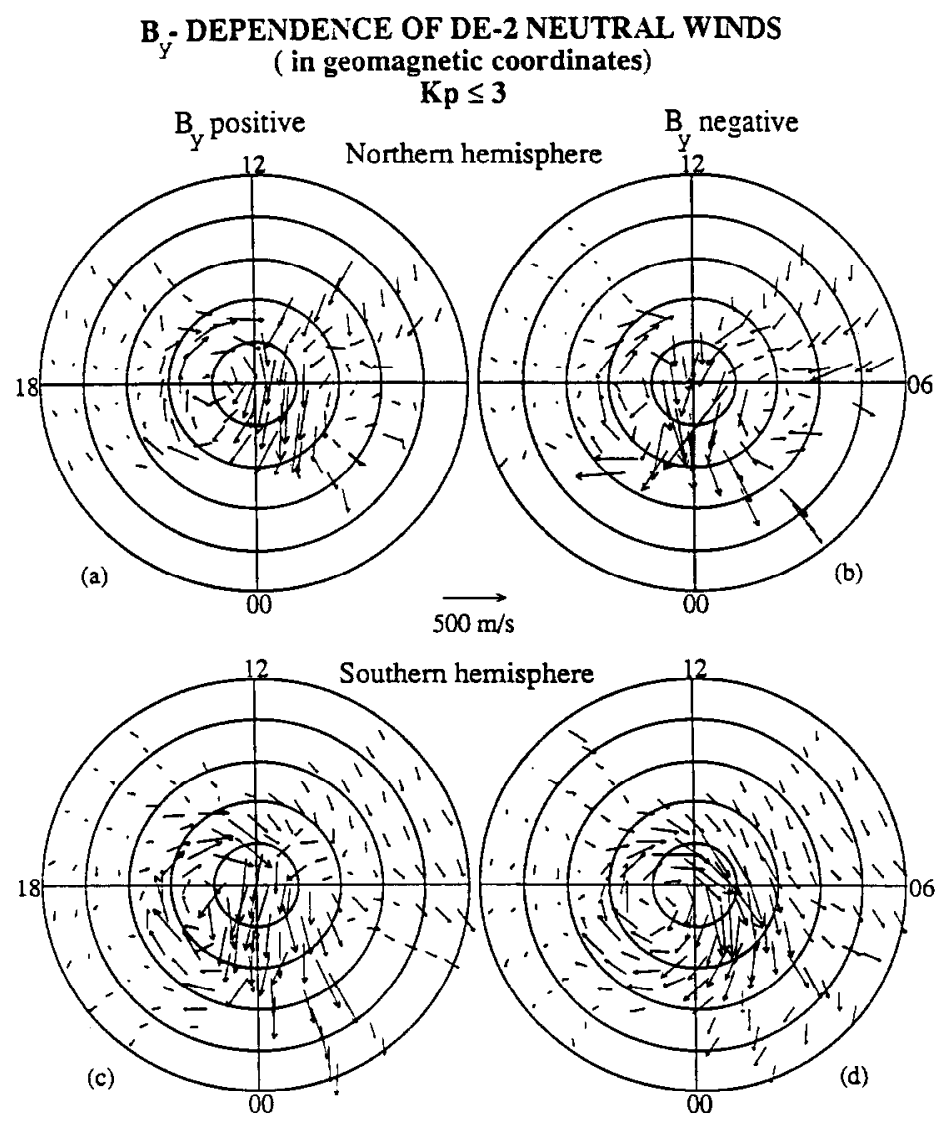

Fig. 5. Averaged upper thermospheric wind measurements for (a) north pole $B_{y}$ positive; (b) north pole $B_{y}$ negative; (c) south pole $B_{y}$ positive; (d) south pole $B_{y}$ negative. Data collected during the same period as for Fig. 4 were averaged according to the sign of the $B_{y}$ component of the IMF and plotted in geomagnetic polar coordinates (magnetic latitude and local time). The outer circle of each polar dial is at $40^{\circ}$ geomagnetic latitude.

The form of the neutral circulation for positive values of $B_{z}$ at high latitudes has also been recently investigated. The existence of a region of sunward neutral wind flow in the central geomagnetic polar cap was noted by KILLEEN et al. (1985) for conditions of persistent large positive values of $B_{z}$. Two examples taken from this study are shown in Fig. 7. These two orbits (7210 and 7211) occurred during a prolonged period of strongly northward IMF $\left(B_{z} \sim 40 \mathrm{nT}\right)$ and both the ion drift measurements (red bars) and neutral winds (blue arrows) showed a region of sunward flow inside the geomagnetic polar cap. In a later study, MCCormac et al. (1991) systematically investigated the conditions for the occurrence of sunward polar cap neutral flow for northward $B_{z}$ as a function of $B_{y}$ using the entire DE 2 data base. They found that sunward winds generally only occurred when (i) $B_{z}$ was persistently positive and (ii) the magnitude of $B_{y}$ was less than the magnitude of $B_{z}$. Figure 8, taken from the McCormac et al. study, is a scatter plot illustrating the IMF conditions for the occurrence of sunward (crosses) and anti-sunward (circles) neutral polar-cap flow. A total of 66 orbits were included in this study; in all cases the hourly averaged IMF $B_{z}$ had been greater than $1 \mathrm{nT}$ positive for the $4 \mathrm{~h}$ prior to the polar-cap orbital pass. It can be seen from this figure that sunward winds inside the polar cap rarely occur when the magnitude of the $B_{y}$ component is greater than the magnitude of the corresponding $B_{z}$ component (i.e. most occurrences of sunward flow [crosses] occur in the uppper triangular section of the plot). This complex dependence of the neutral wind morphology on the relative magnitudes of individual IMF components is a phenomenon that clearly demonstrates the strong coupling among the magnetosphere, ionosphere and thermosphere. 


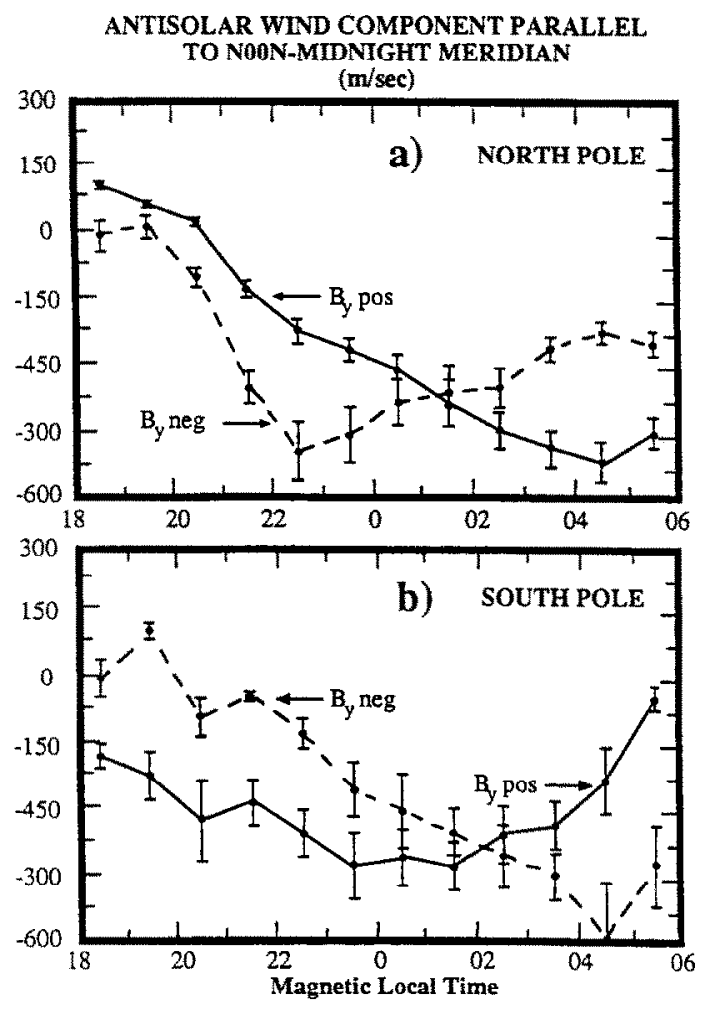

Fig. 6. Average anti-sunward neutral wind component parallel to the noon-midnight meridian in meters per second on the night side of the geomagnetic polar cap for both signs of $B_{y}$ in the (a) northern and (b) southern hemispheres. The wind components have been averaged over magnetic latitudes between 72.5 and $87.5^{\circ}$ and for each hour of magnetic local time from 1800 to 600 . The figure is taken from THAYER (1990).

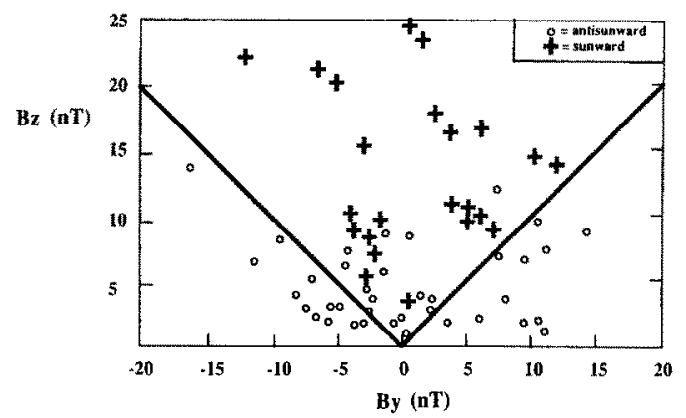

Fig. 8. Scatter plot of sunward and anti-sunward winds near the center of the geomagnetic polar cap as a function of the relative magnitudes of the $B_{y}$ and $B_{z}$ components of the interplanetary magnetic field. A total of 66 orbits are included in the plot. For all of the included orbits, the hourly averaged IMF $B_{z}$ had been greater than $1 \mathrm{nT}$ positive for the previous $4 \mathrm{~h}$. This figure is taken from MCCormac at al. (1991).

\subsection{Vorticity and divergence in the high-latitude ther- mospheric wind pattern}

The averaged measurements of thermospheric winds from DE 2 have enabled a study of the vorticity and divergence in the global-scale mean neutral flow in the high-latitude thermosphere to be conducted for the first time (THAYER and KilleEN, 1991). In this work, data from two separate three-month intervals, centered on the winter solstices of 1981-1982 and 1982-1983, were averaged and binned according to geomagnetic latitude (MLAT) and local time (MLT). The DE 2 data were then analysed spectrally and merged with VSH model predictions as described by Thayer and Killeen to provide maps of the vorticity and divergence fields for (i) low geomagnetic activity and (ii) moderately high geomagnetic activity. These maps are shown in Fig. 9 for the northern hemisphere, winter case. Figure $9 \mathrm{a}$ and $\mathrm{c}$ shows the vorticity maps in geomagnetic polar coordinates for $K_{p} \leqslant 3$ conditions and $3+\leqslant K_{p} \leqslant 6$ conditions, respectively, and Fig. $9 \mathrm{~b}$ and $\mathrm{d}$ shows the divergence maps for the corresponding cases. These fields have been intentionally smoothed by the spectral truncation schene used in manipulating the satellite data and they therefore represent the mean vorticity and divergence fields for the periods November 1981-January 1982, inclusive, and November 1982-January 1983, inclusive. Data from all Universal Times (UTs) were used to generate these maps, based on the assumption that the neutral wind field is largely invariant to UT when plotted in geomagnetic coordinates.

The derived vorticity patterns in units of inverse seconds, shown in Fig. 9a and c, describe the rotation in the flow field, where negative (positive) vorticity denotes anti-cyclonic (cyclonic) rotation. Since vorticity is generated by wind shear, the strong antisunward flow over the magnetic pole, combined with sunward flow in the dawn and dusk sectors, creates two regions of counter-rotating flow. Negative vorticity or anti-cyclonic rotation occurs primarily in the dusk sector, with a minimum value of $-518 \times 10^{-6} \mathrm{~s}^{-1}$ for the low $K_{p}$ case and $-596 \times 10^{-6} \mathrm{~s}^{-1}$ for the high $K_{p}$ case. Positive vorticity or cyclonic flow occurs primarily in the dawn sector with a maximum value of $426 \times 10^{-6} \mathrm{~s}^{-1}$ for the low $K_{p}$ case and $559 \times 10^{-6} \mathrm{~s}^{-1}$ for the high $K_{p}$ case. By comparing the vorticity fields for low and high $K_{p}^{\prime}$, it is evident that an enhancement in geomagnetic activity leads to enhanced vorticity in both dawn and dusk sectors and a general growth in the size of the region dominated by the twin vortices. The demarcation line of zero vorticity marks the region of shear reversals where the wind either reaches a maximum in the anti- 


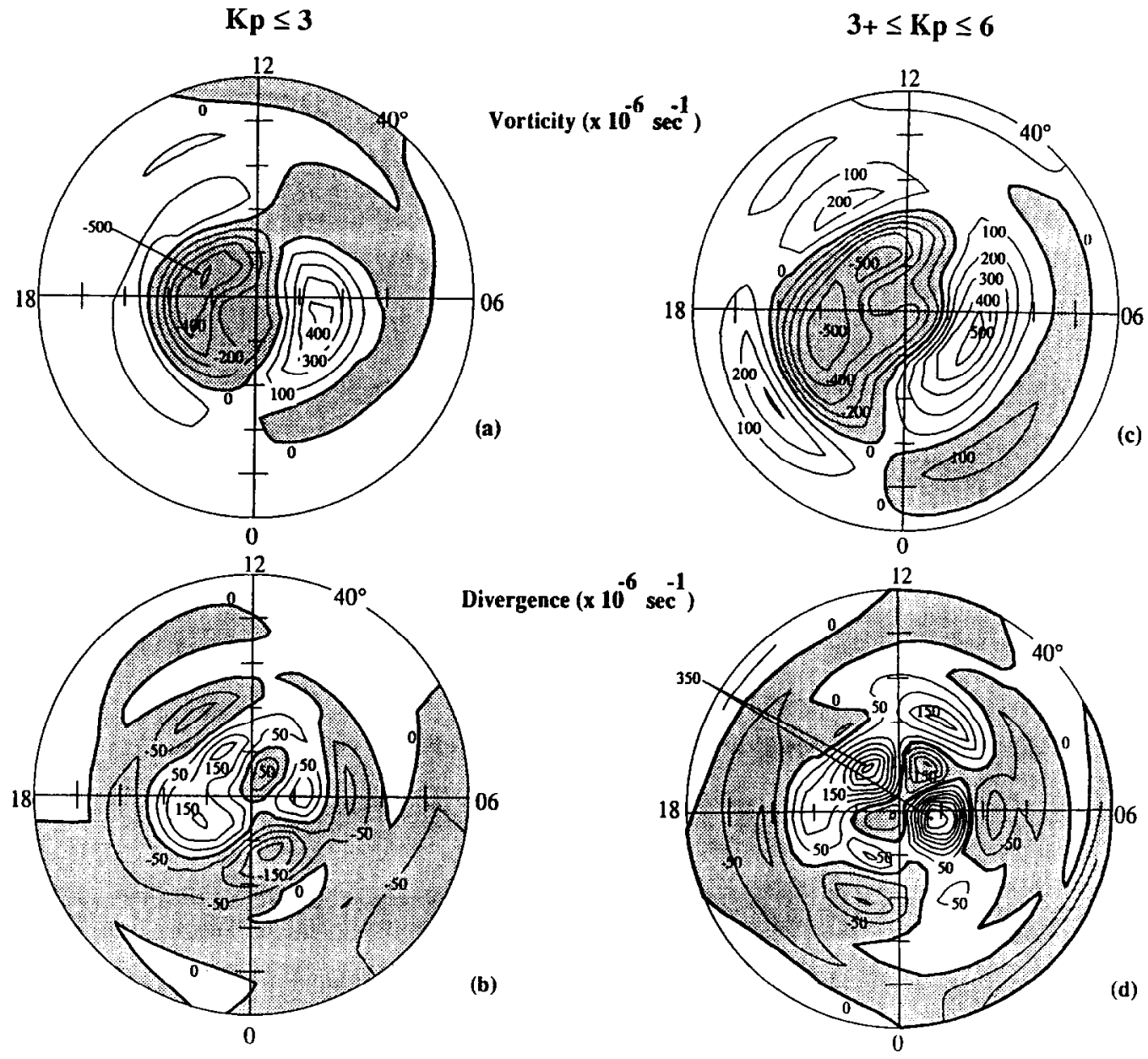

Fig. 9. Derived (a) vorticity pattern for the winter polar thermosphere at $\sim 300 \mathrm{~km}$ altitude for conditions of low geomagnetic activity (northern hemisphere); (b) corresponding divergence pattern; (c) vorticity pattern for moderately active geomagnetic conditions; (d) corresponding divergence pattern. The patterns are shown in geomagnetic polar coordinates (magnetic latitude: pole to $40^{\circ}$ and magnetic local time). The contour interval is $100 \times 10^{-6} \mathrm{~s}^{-1}$ for the vorticity plots and $50 \times 10^{-6} \mathrm{~s}^{-1}$ for the divergence plots. These plots were generated from spectrally analysed DE 2 data and VSH model predictions (from THAYER and KILLEEN, 1991).

sunward direction in the central polar cap, or a maximum in the sunward direction in the dawn and dusk sectors. Thus, the transitions in the vorticity fields may be used to define the spatial dimensions of the high-latitude neutral circulation pattern. Below $\sim 60^{\circ}$ MLAT, the vorticity values are relatively small. The dominance of the signatures of the twin vortex motion induced in the high-latitude thermosphere by ion drag processes is evident in these maps which are strongly reminiscent of similar-looking maps of equipotentials for the polar electric fields (e.g. HEPPNER, 1977; HEELIS et al., 1982).
The derived divergence patterns, shown in Fig. $9 \mathrm{~b}$ and $\mathrm{d}$, describe the rate of change of area in the flow ficlds determincd by the longitudinal difference in the zonal wind components and the latitudinal difference in the meridonal wind components, where negative values denote convergence in the flow field and positive values denote divergence. Once again, these fields represent mean patterns for the epoch in question and are plotted in units of inverse seconds. It can be seen that the divergence values are generally smaller (by about a factor of 4) than the vorticity values discussed above. This is due to the greater importance of the 
largely divergence-free ion-drag momentum term in establishing the neutral circulation. Perturbations in the divergence fields are primarily forced by localized regions of heating, which can lead to upwelling and positive divergence, or regions of relative cooling, which can lead to downwelling or negative divergence (convergence). The divergence patterns are more complex than their vorticity counterparts and are characterized by localized islands of positive and negative divergence associated with regions of high-latitude heating and subsidence. The effect of enhanced levels of geomagnetic activity is to widen the area of large perturbations in the divergence fields and to intensify the maxima and minima observed. In these localized regions, the divergence field becomes commensurate with the vorticity field in magnitude.

The ability to generate thermospheric vorticity and divergence maps such as those shown in Fig. 9, provides a new tool for the interpretation of high-latitude thermospheric circulation patterns, allowing for a more detailed kinematic analysis of the flow configurations. In particular, this novel tool gives additional insight into the relative strengths of the various sources of momentum and energy responsible for driving the winds.

\section{THE VECTOR SPHERICAL HARMONIC MODEL}

The Vector Spherical Harmonic (VSH) model has been described by KilLEEN et al. (1987). It is a semiempirical 'hybrid' model that is based on numerical simulations of the NCAR-TIGCM and available experimental data from DE 2. The NCAR-TIGCM solves the primitive equations of dynamic meteorology adapted to thermospheric altitudes, including equations for the conservation of energy and momentum and the individual species continuity equations. The physics inherent in the model's parameterizations and input prescriptions are those appropriate to thermospheric altitudes. The basic model and subsequent major developments have been described in detail by DiCKINSON et al. (1981, 1984), RoBle et al. (1982), FESEN et al. (1986) and RoBle and RidLey (1987). Most recently, the model was further extended (RoBLE et al., 1988) to include a self-consistent aeronomic scheme for the thermosphere and ionosphere using a fully Eulerian approach.

The VSH model uses output from various 'generic' runs of the TIGCM to develop a library of truncated spectral coefficients that represent the global thermospheric wind, temperature and neutral composition fields for a set of different geophysical conditions (solar maximum, solar minimum, equinox, solstice, etc.). The three-dimensional wind field is represented by a vector spherical harmonic cxpansion in the horizontal, a Fourier expansion in Universal Time and a polynomial expansion in altitude. The global temperature field differs in that a scalar spherical harmonic expansion is used in the horizontal and a Bates model profile is used in the vertical. Neutral composition fields are described using logarithmic scalar harmonic expansions. The thermospheric state variables (wind, temperature and composition) may then be calculated simply using a computer subroutine which reads in the coefficients and regenerates the required field as a function of space and time and geophysical condition ( $F 10.7$ value and $\left.A_{p}\right)$. Recently, data from DE 2 have also been incorporated into the VSH model description using an objective analysis scheme to merge the experimental data and theoretically calculated TIGCM gridded output fields. In this objective analysis scheme, measurements from DE 2 are used whenever available, and TIGCM model results are used in the absence of experimental data, with the whole process being carried out in the spectral domain to provide for smooth merger of the experimental and theoretical results.

\subsection{VSH model comparisons with thermospheric wind observations}

An example of a comparison between the global output of the VSH model and averaged DE 2 data is shown in Fig. 10. The lower part of this figure (10b) shows the bin-averaged neutral wind field from FPI and WATS as a function of UT and latitude, coded as vectors, for the same two three-month study periods as for the previous results shown earlier. The thermospheric temperatures from FPI and WATS are coded as colors according to the scale at the right. As can be seen, the largest wind speeds are observed in the two high-latitude regions (southern hemisphere polar regions towards the lower part of the plot and northern hemisphere polar regions towards the upper part). The measured thermal structure indicates a relatively hot summer polar region (temperatures up to $\sim 1500 \mathrm{~K}$ ) and a relatively cold low-latitude region (blue band in middle of plot - temperatures $\sim 900 \mathrm{~K}$ ). For comparison, Fig. 10a shows the equivalent output from the VSH model, where the model was interrogated to provide calculated December solstice wind and temperature fields in the same format as the experimental data. As can be seen, there is reasonable agreement between the model and the global-scale experimental data. The seasonal thermal structure (summer-to-winter gradient) is present in the model which, however, tends to underestimate the northern polar 
temperatures. The wind pattern shows reasonable agreement also, though there is considerably more structure in the experimental results than in the model predictions. The morphology of the high-latitude flows and reversals are generally well matched by the model.

To provide additional comparisons with the new VSH model, Figs 11 and 12 show comparisons with ground-based thermospheric neutral wind measurements. Fig. 1la shows thermospheric wind measurements from two optical observatories in Greenland, one at Thule $\left(76.0^{\circ} \mathrm{N}, 70.0^{\circ} \mathrm{W}\right)$ in the central region of the geomagnetic polar cap and one at Sondrestrom $\left(67.0^{\circ} \mathrm{N}, 51.0 \mathrm{~W}\right)$ on the northern edge of the auroral zone. The winds shown represent bin-averaged data for geomagnetic quiet times $\left(K_{p} \leqslant 3\right)$, taken during the 1987-1988 observing season (September-March). The vectors shown represent bin-averaged winds at $\sim 250 \mathrm{~km}$ altitude from both stations for all available clear nights of observations during low geomagnetic activity conditions $\left(K_{p} \leqslant 3\right)$, plotted in polar geographic coordinates. The inner set of vectors show the averaged winds from Thule and the outer set of vectors show the winds from Sondrestrom. For comparison, Figure $11 \mathrm{~b}$ shows the output from the VSH model which was interrogated to match the conditions appropriate to the experimental results. The measured winds show a largely anti-sunward flow over the polar cap, bounded on the dusk side with a region of sunward flow, and with a turning and abatement of the winds on the dawn side of the polar cap. The comparison between experiment and model indicates reasonable agreement, with the major characteristics of the flow pattern being well represented by the model. There are some discrepancies, however, notably in the direction of the strong anti-sunward flow over Sondrestrom near midnight.

Figure 12 shows experimental neutral wind data from the incoherent scatter radar at Sondrestrom, separated according to the sign of the IMF $B_{y}$ component. These data represent approximately $2200 \mathrm{~h}$ of measurements obtained between April 1983 and July 1988. The radar winds are averaged between 210 and $360 \mathrm{~km}$ altitude. The VSH model was interrogated to provide predictions for the neutral winds during these periods and these results are shown in Fig. 12. The agreement between the VSH model predictions and the radar-determined winds for the given site is again reasonable, perhaps with the exception of the early morning period for $B_{y}$ positive where the model overestimates the magnitude of the measured wind. Since the empirical component of the VSH model is provided by DE 2 measurements referred to the 19811983 solar maximum period, it is encouraging to note
Thule and Sondre Stromfjord FPI $-K p \leq 3,1987 / 8$

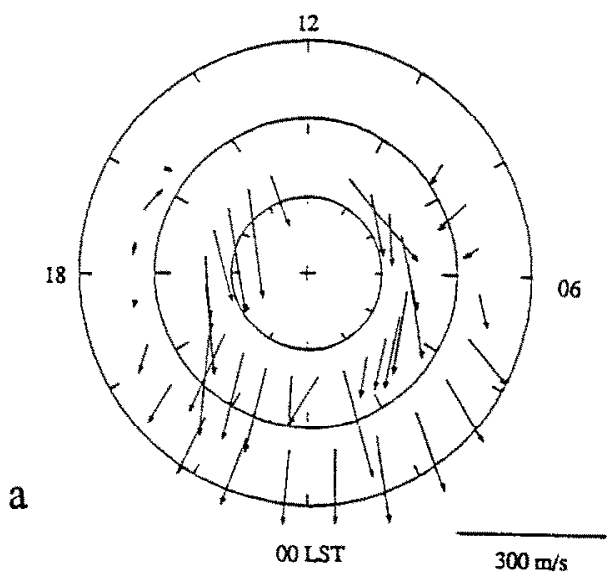

Thule and Sondre Stromfjord - VSH winds, solar min., low Kp

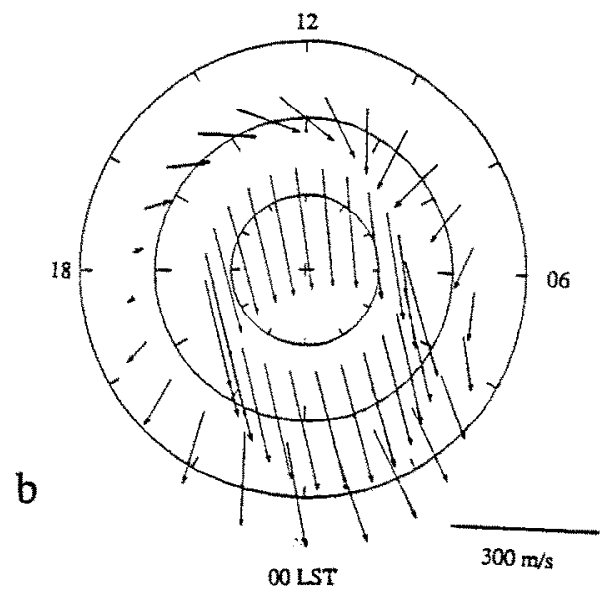

Fig. 11. (a) Measured neutral winds at $\sim 250 \mathrm{~km}$ altitude determined from the Fabry-Perot observatories at Thule, and Sondrestrom, Greenland, during the observing season of 1987-1988. The data represent bin-averaged winds for all clear-sky observations from the two stations. The winds are coded as arrows (scale at lower right) with the base of the arrow located at the appropriate local time and latitude for the particular station. The Thule measurements constitute the inner circle of vectors and the Sondrestrom measurements constitute the outer circle of vectors. (b) VSH model predictions for the corresponding geophysical conditions.

the degree of model agreement with neutral wind data obtained from a quite different time period and phase of the solar cycle.

\section{THERMOSPHERIC COMPOSITION PERTURBATIONS AT HIGH LATITUDES}

The results described above have demonstrated various characteristics of the mean thermospheric 
By $<0$

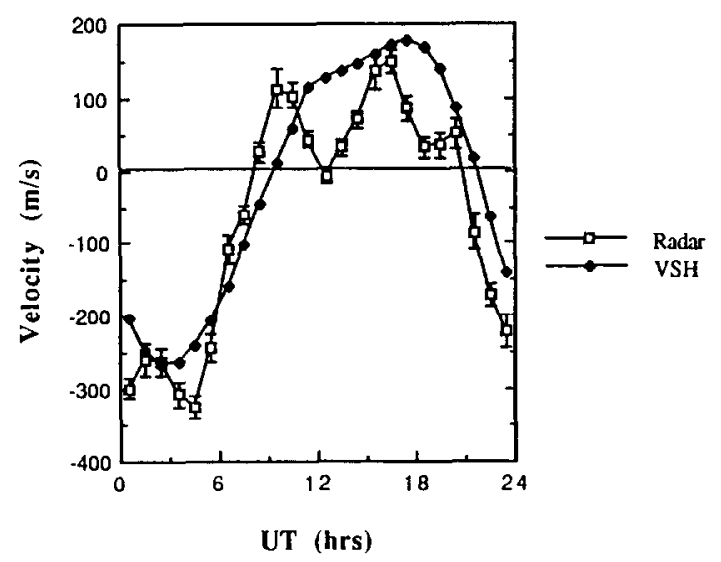

By $>0$

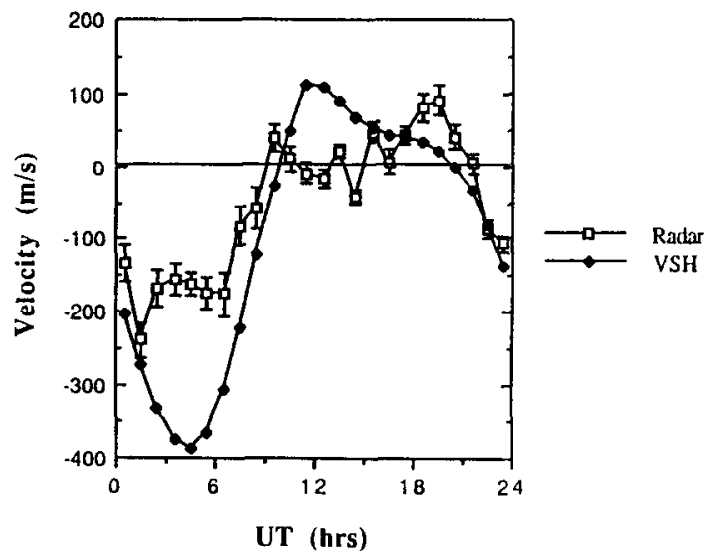

Fig. 12. Comparison of Sondrestrom incoherent scatter radar average meridional winds (in the magnetic meridian) with predictions of the Vector Spherical Harmonic Model (KILLEEN et al., 1987) as a function of IMF $B_{y}$ orientation for $B_{z}$ negative conditions. The radar data set includes approximately $2200 \mathrm{~h}$ of measurements obtained from April 1983 to July 1988. Radar winds were first averaged over hourly intervals from 210 to $360 \mathrm{~km}$ for each experiment. The average winds as a function of UT and IMF orientation were then determined by binning the entire data set as a function of UT hour and average IMF orientation during the period from 1 to $2 \mathrm{~h}$ prior to the beginning of each hourly bin. The figure is taken from JoHNSON et al. (1991).

neutral circulation at high geomagnetic latitudes. The wind patterns show a circulation that has a strong rotational component associated with the twin-cell ionospheric convection pattern, with a significant divergent component driven largely by pressure gradient forcing. It might be expected that the large maynitude horizontal neutral winds and associated vertical motions would have a significant effect on the compositional balance of the upper thermosphere. To investigate this possibility, BURNS et al. (1989) have used the NCAR-TIGCM to study the changes in thermospheric composition that result from wind systems such as discussed above. Figure 13 shows an example of a set of calculations from their work, illustrating the various dynamical forcing terms for thermospheric composition variations during and in the aftermath of a simulated geomagnetic storm.

This figure shows NCAR-TIGCM calculations of the terms responsible for changes in the mass mixing ratio of $\mathrm{N}_{2}\left(\Psi_{\mathrm{N}_{2}}\right)$ during the large geomagnetic storm that occurred on 24 November 1982. The terms are referred to an altitude of $\sim 280 \mathrm{~km}$ and the location of the geomagnetic pole is shown as the cross in Fig. $13 \mathrm{~d}$. The plots show the differences between storm and quiet times for the following terms: (a) vertical advective forcing of $\Psi_{N_{2}}$; (b) horizontal advective forcing of $\Psi_{\mathrm{N}_{2}}$; (c) molecular diffusion effects and (d) $\Psi_{\mathrm{N}_{2}}$ itself. The first three plots (13a-c), showing com- positional adjustment forcing terms, are for $14 \mathrm{UT}$, some $3 \mathrm{~h}$ after the commencement of the storm, and the plot showing the mass mixing ratio (13d) is for 19 UT or $2 \mathrm{~h}$ into the storm simulation. Thus, these plots illustrate some of the physical forcing processes that give rise to the changes in mass mixing ratio at $\sim 280 \mathrm{~km}$ a few hours after the commencement of a large geomagnetic storm.

The pattern of compositional forcing that is seen at high latitudes for this storm-time case results from both horizontal and vertical advection, where the horizontal and vertical winds are due primarily to ion drag and Joule heating, respectively. Figure 13a illustrates the rate of change of mass mixing ratio duc to the advective effects of vertical winds. A region of positive values (associated with upwelling near regions of enhanced heating) can be seen to be roughly coincident with the location of the auroral zone and regions of negative forcing (associated with subsidence) can be seen to lie equatorward of the auroral zone and within the geomagnetic polar cap. Figure 13b illustrates the rate of change of $\Psi_{N_{2}}$ due to the advective effects of horizontal winds. The region of large positive values in the post-midnight sub-auroral sector is due to the existence of the post-midnight surge in the meridional winds which tends to increase the mass mixing ratio of nitrogen downstream from the polar regions. Figure $13 \mathrm{c}$ illustrates the rate of change 

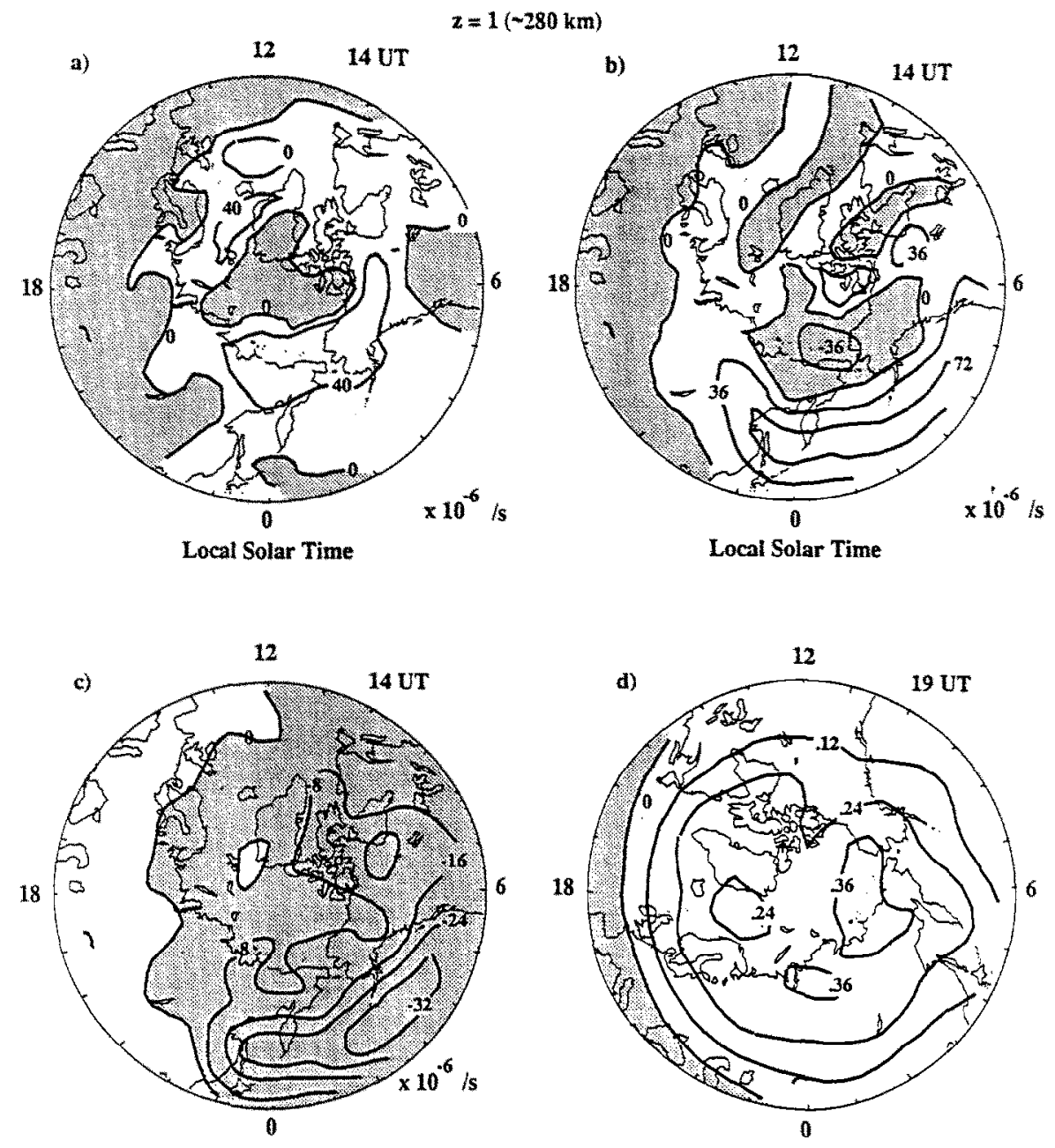

Local Solar Time

Local Solar Time

Fig. 13. NCAR-TIGCM calculations of the forcing terms responsible for changes in the mass mixing ratio of $\mathrm{N}_{2}\left(\Psi_{\mathrm{N}_{2}}\right)$ during the large geomagnetic storm that occurred on 24 November 1982 . The plots show the mass-mixing-ratio forcing-term differences between storm and quiet times for the following: (a) vertical advection; (b) horizontal advection; (c) molecular diffusion and (d) ( $\Psi_{\mathrm{N}_{2}}$ ). The first three terms ate for $14 \mathrm{UT}$, some $3 \mathrm{~h}$ after the commencement of the storm, and the last plot, showing mass mixing ratio, is for

19 UT. The cross in Fig. $13 \mathrm{~d}$ indicates the location of the geomagnetic pole.

of $\Psi_{N_{2}}$ due to molecular diffusion. This term tends to be negative throughout the high-latitude region as it attempts to restore the thermosphere to the diffusive equilibrium that has been interrupted by the highlatitude dynamical processes. Maximum values of the perturbed $\Psi_{N_{2}}$ (Fig. 13d) are found in the auroral and sub-auroral morning sector, in agreement with the DE 2 observations reported by HEDIN and CARIGNAN (1985). The magnitudes of the three terms shown in
Fig. $13 a-c$ are roughly commensurate, indicating that all three processes (vertical and horizontal advection and molecular diffusion) are of roughly equal importance in the establishment of the storm-time compositional state of the high-latitude thermosphere. This type of quantitative compositional forcing term analysis thus enables a deeper insight into the coupling of dynamics and composition in the high-latitude thermosphere. 


\section{CONCLUDING REMARKS}

Recent experimental results from the Dynamics Explorer-2 spacecraft and ground-based optical and radar observatories have illustrated the manner by which the high-latitude processes of ion drag and Joule heating control the behavior of the high-latitude upper thermosphere. The neutral winds at high altitudes typically tend to follow the twin-cell pattern of ionospheric convection, as momentum is transferred from the ions to the neutrals at a rate that is proportional to the ion density. As a consequence of this tight ion-neutral momentum coupling, the neutral wind pattern displays strong dependencies on the level of geomagnetic activity and on the orientation of the interplanetary magnetic field, much in the same way as the ionospheric convection pattern does itself. Neutral wind vortices are established whose geometries and intensities depend on the nature and time-history of the momentum forcing. Upper thermospheric temperatures are directly controlled by the Joule and particle heat sources associated with auroral latitudes. The auroral heating also serves to modulate the thermospheric circulation through the generation of strong pressure-gradient forces and through local upwelling of the atmosphere. Changes in the vertical and horizontal winds at high latitudes lead, in turn, to neutral compositional perturbations. The various dynamical, energetic and compositional variations associated with auroral processes are thus highly coupled with each other.

Significant progress has been made recently in the development of semi-empirical models of the thermosphere that utilize the large and comprchensive new data resources. One of these models, the Vector Spherical Harmonic model, has been shown to provide reasonably accurate predictions for global-scale thermospheric wind systems.

Acknowledgements-This work was supported by the NASA grant NAG5-465 and by NSF grants ATM-8918476, ATM8822530 , ATM 9096134 and ATM 9002608 and by Geophysics Laboratory grant F19628-89-K-0047 to the University of Michigan. Dynamics Explorer science team members who kindly provided data for this work include Drs R. A. Heelis, W. B. Hanson, L. A. Frank, J. D. Craven, L. H. Brace, W. R. Hoegy, N. W. Spencer and G. R. Carignan. We also thank Dr R. G. Roble for numerous discussions and for providing TIGCM model results.
Burns A. G., Kulleen T. L. and Roble R. G. Carignan G. R., Block B. P., Maurer J. C., Hedin A. E., Reber C. A. and SPENCER N. W. Dickinson R. E., RiDley E. C. and Roble R. G. Dickinson R. E., RidLey E. C. and Roble R. G. Fesen C. S., Dickinson R. E. and Roble R. G. Frank L. A., Craven J. D., Ackerson K. L., ENGLISH M. R., EATHER R. H. and Carovillano R. L.

Fuller-Rowell T. J, Quegan S., ReEs D., MOFFETT R. J. and BAILEY G. J.

Fuller-Rowell T. J. and ReEs D.

Hanson W. B., Heelis R. A., Power R. A., LippincotT C. R., Zuccaro D. R., Holt B. J. HARMON L. H. and Sanatani S.

Hays P. B., Killeen T. L. and Kennedy B. C.

Hays P. B., Killeen T. L., Spencer N. W. Wharton L. E., Roble R. G., Emery B. A., Fuller-Rowell T. J., Rees D., Frank L. A. and CRAven J. D.

Hedin A. E., Biondi M. A., Hernandez G., Burnside R. G., JoHnSON R. M., KilleEN T. L., Mazaudier C., Meriwether J. W., Salah J. E., SICA R. J., SMith R. W., SPENCER N. W., WICKWAR V. B. and VIRDI T. S.

Hedin A. E and Carignan G. R.

Hedin A. E., Spencer N. W. and Killeen T. L. Heelis R. A., Hanson W. B., LippincotT C. R., Zuccaro D. R., Harmon L. H., Holt B. J., Doherty J. E. and Power R. A.

Heelis R. A., Lowell J. K. and Spiro R. W. HEPPNER J.P.

\section{REFERENCES}

1989 J. geophys. Res. 94, 3670.

1981 Space Sci. Instrum. 5, 493.

$1981 \quad J$ geophys. Res. 86, 1499.

1984 J. atmos. Sci. 41, 205.

$1986 J$ Jeophys. Res. 91, 4471.

1981 Space Sci. Instrum. 5, 369.

1987 J.geophys. Res. 92, 7744.

1980 J. atmos. Sci. 37, 2545.

1981 Space Sci. Instrum. 5, 503.

1981 Space Sci. Instrum. 5, 395.

1984 J.geophys. Res. 89, 5597.

$1991 J$ Jeophys Res. 96, 7657.

$1985 J$ Jeophys. Res. 90, 5269.

1988 J.geophys. Res. 93, 9959.

1981 Space Sci. Instrum. 5, 511.

$1982 J$ Jeophys. Res. 87, 6339.

1977 J.geophys. Res. 82, 1115. 
JoHNSON R. M., DE LA BEAYjardiere O. and Killeen T. L.

KILLEEN T. L.

Killeen T. L., Craven J. D., Frank L. A., Ponthieu J.-J., Spencer N. W., Heflis R. A. Brace L. H., Roble R. G., Hays P. B. and CaRignan G. R.

Killeen T. L., Hays P. B., Spencer N. W. and WHARTON L. E.

Killeen T. L., Heelis R. A., Hays P. B., SPENCER N. W, and HaNSON W. B.

KULLEN T. L. and RuBLE R. G.

KILLEEN T. L. and ROBLE R. G.

KILLEEN T. L., ROBLE R. G. and SPENCER N. W.

Krehaiel J. P., Brace L. H., Theis R. F., Pinkus $W . H$. and Kaplan R. B.

MaYr H. G.. Harris I., Varosi F. herrero F. A., Volland H., Spencer N. W., Hedin A. E., Hartle R. E., Taylor H. A. JR, Wharton L. E. and Carignan G. R.

MCCORMAC F. G., KILLEEN T. L. and THAYER J.P.

McCormac F. G., Killeen T. L., Thayer J. P., Tschan C. R., Hernandez G., Ponthteu J.-J. and SPENCER N. W.

MERIWETHER J. W. JR

Rees D., Gordon R., Fuller-Rowell T. J., Smith M., Carignan G. R., Killeen T. L., HAYS P. B. and SPENCER N. W.

ROBLE R. G.

Roble R. G., Dickinson R. E. and RIDLEY E. C.

Roble R. G., Dickinson R. E., Ridley E. C., EMERY B. A., Hays P. B., KILllen T. L. and SPENCER N. W.

Roble R. G. and Ridley E. C.

Roble R. G., Ridley E. C., Richmonis A. D. and DiCKINSON R. E.

Spencer N. W., Wharton L. E., Niemann H. B., Hedin A. E., Carignan G. R. and MAURER J. C.

Thayer J. P. and Killeen T. L.

Thayer J. P., Killeen T. L., MCCormac F. G., Tschan C, R., PONTHIEU J.-J and SPENCER N. W.

Reference is also made to the following unpublished material:

THAYER J. P.
1991 J.geophys. Res. (unpublished manuscript).

1987 Rev. Geophys. 25, 433.

$1988 \quad$ J.geophys. Res. 93, 2675.

1982 Geophys. Res. Lett. 9,957.

1985 Geophys. Res. Lett. 12, 159.

$1984 \quad J$. geophys. Res. 89, 7509.

1988 Rev. Geophys. 26, 329.

1987 Adv. Space Res. 7, 207.

1981 Space Sci. Instrum. 5, 493.

1985 Adw. Space Res. 5, 283.

1991 J.geophys. Res. 96, 115.

1987 J.geophys. Res. 92, 10133.

1983 Radio Sci. 18, 1035.

1985 Planet. Space Sci. 33, 617.

1983 Rev. Geophys. Space Phys. 21, 217.

1982 J.geophys. Res. 87, 1599.

1983 Planet. Space Sci. 31, 1479.

1987 Ann. Geophys. 5A, 369.

1988 Geophys. Res. Lett. 15, 1325.

1981 Space Sci. Instrum. 5, 417.

1991 J. geophys. Res. (unpublished manuscript).

1987 Ann. Geophys. 5A, 363.

Ph.D. thesis, University of Michigan, Ann Arbor, MI 48109, U.S.A. 